Por que a mídia é tão parcial e adversária da minha posição? A hipótese da 'hostile media perception'

[Why is the media so biased against my opinion? The 'hostile media perception' hypothesis]

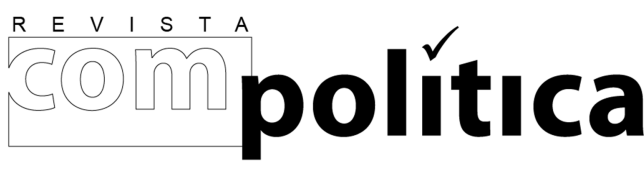

revista compolítica 2016, vol. 6(1)

compolitica.org/revista

ISSN: 2236-4781

DOI: 10.21878/compolitica.2016.6.1.262

Open Access Journal

\author{
Wilson Gomes \\ Universidade Federal da Bahia \\ [Federal University of Bahia]
}

\begin{abstract}
Resumo
O trabalho discute o muito disseminado sentimento, que afeta os membros de certos grupos e em certas circunstâncias, de que os meios de comunicação são tendenciosos contra o nosso lado e favorecem o lado adversário, assim como os mecanismos que lhe são subjacentes. Este ensaio tem como foco a sensação, convicção ou opinião, compartilhada por pessoas altamente envolvidas com certos temas ou assuntos, de que os conteúdos e abordagens da mídia são tendenciosos e adversários se e quando incongruentes com o ponto de vista ideológico, político ou religioso do próprio sistema de referências intelectual, moral e afetivo. Para tanto, o artigo resenha os argumentos mais constantes nos quase trinta anos de literatura especializada sobre a "hostile media perception" (HMP), modelo teórico-metodológico importante no campo dos estudos dos efeitos da comunicação, resumindo pontos de vista e apontando direções da pesquisa.
\end{abstract}

Palavras-chave: manipulação da mídia; imparcialidade no noticiário; sensação de mídia hostil; jornalismo político.

\title{
Abstract
}

This paper discusses the highly widespread impression that the media is biased against us and favorable to the opposing view, as well as the mechanisms underlying this social perception that affect members of certain groups in specific circumstances. This essay, is concerned with the perception or opinion, shared by those highly involved with certain topics or subjects, that the news media content is biased and hostile, if and when it is perceived to be incongruent with the ideological, political or religious perspectives adopted by a partisan intellectual, moral and affective system of reference. To this end, this article examines the most common arguments found in nearly thirty years of literature on "hostile media perception" (HMP), an important line of research in the study of media effects that is, curiously, not yet well-known in Brazil, by summarizing viewpoints and exploring research possibilities.

Keywords: media bias; news bias; media hostile perception; political journalism. 


\section{Por que a mídia é tão parcial e adversária da minha posição? A hipótese da 'hostile media perception'}

Wilson GOMES

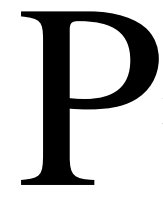

ergunte às pessoas se elas acham o noticiário tendencioso e a resposta predominante vai ser afirmativa, principalmente em períodos eleitorais. E será assim em toda a parte do mundo, mesmo naqueles lugares em que nós consideramos, em geral, que os meios de comunicação funcionam em favor da democracia. Se formos mais específicos, não perguntando sobre o noticiário ou "a mídia" em geral, mas sobre o veículo $\mathrm{X}$ ou $\mathrm{Y}$ ou a matéria $\mathrm{A}$ ou $\mathrm{B}$, verificaremos a persistência da mesma sensação: boa parte das pessoas acha que os jornais e os seus conteúdos têm, sim, inclinações. Inclinações políticas, ideológicas, religiosas. Inclinação pode ainda ser uma palavra neutra, uma vez que diz respeito apenas às preferências adotadas no nível dos valores: na verdade, as pessoas tendem a qualificar essas inclinações como distorções. O sentimento mais difuso, portanto, é que os meios de comunicação sejam, na verdade, tendenciosos. Esta convicção de que há "tendenciosidade", como se diz popularmente, é o que um bom montante de literatura internacional sobre os efeitos da comunicação chama de percepção ou convicção de "media bias" ou "news bias", é a sensação de que os meios de comunicação distorcem os fatos.

Esta sensação é constantemente confirmada em sondagens de opiniões. Nos Estados Unidos, por exemplo, pesquisa do The Pew Research Center, de 2011, descobriu que nada menos que $66 \%$ dos americanos achavam que as notícias publicadas eram inexatas, $77 \%$ consideravam que o jornalismo sempre favorece um dos lados, enquanto $80 \%$ acreditavam que os meios de comunicação são influenciados por organizações e indivíduos poderosos (GLYNN; HUGE, 2014). Não conhecemos dados sistemáticos sobre o Brasil, mas dificilmente serão muito diferentes desses. Naturalmente, em diferentes "culturas políticas" (significados e valores político-partidários e ideológicos compartilhados socialmente) as pessoas compartilham diferentes visões sobre o lado favorecido na inclinação da mídia. Nos Estados Unidos, assim diz a bibliografia, predomina o chamado "mito da mídia liberal", com republicanos e conservadores 
revelando maior propensão a desconfiar da mídia e das suas inclinações democratas e liberais (LEE, 2005), enquanto no Brasil se compartilha como se fosse evidência a ideia de que "a grande mídia" é de direita e francamente adversária de posições politicamente progressistas e de esquerda. Durante o período eleitoral de 2014, e logo depois dele, entretanto, foi notável como grupos muito diferentes entre si, como conservadores religiosos, ultradireitistas e a esquerda tradicional, alternavam-se na enunciação de que os grandes jornais brasileiros assumiram uma posição acintosamente favorável aos seus adversários.

Teria esta sensação fundamento na realidade? É mesmo verdade que grande parte dos noticiários, dos veículos e das matérias seja tendenciosa? A sensação de que o noticiário é distorcido poderia ter alguma outra origem além do fato, simples e puro, de que o noticiário é efetivamente tendencioso? As pessoas são inclinadas, naturalmente, a achar que os seus sentimentos, ainda mais quando eles têm o apoio e o reforço dos coletivos em que se inserem, correspondem inteiramente à realidade: se acho que os jornais são tendenciosos e os meus amigos também acham o mesmo, por que teria razão para duvidar de que isso espelha o que os jornais realmente são? Como crença não faz boa ciência, quem tem que se munir de algum ceticismo, ao menos metodológico, é o pesquisador, sob pena de ver-se enganado pelas cortinas de obviedade. Então, vale à pena investigar o que há por trás da sensação de comunicação distorcida.

Por anos, a pesquisa em comunicação explicou muito pouco das origens da atitude cética acerca da cobertura jornalística. A razão disso é que, por um período relativamente longo, aceitou-se, pelo valor de face, a tese de que características do jornalismo são o que explica a desconfiança quanto à sua incapacidade de produzir coberturas justas e imparciais sobre os fatos. A descrença na justeza da cobertura seria decorrente da parcialidade da fonte, o próprio jornalismo - a experiência com jornais e jornalismos objetivamente parciais produziria a sensação subjetiva de que o jornalismo é tendencioso, como regra de fato. Nesses casos, a unidade de análise é normalmente um jornal ou revista em particular ou uma instituição jornalística, como a televisão (Gunther, 1992 p. $148)^{1}$. O inconveniente nesta perspectiva, como veremos adiante, é o fato de ser bastante comum que leitores de jornais que são membros de grupos diferentes e adversários vejam 
como parciais as mesmas matérias sobre fatos aos quais são muito sensíveis, mas cheguem a divergir fortemente sobre para que lado pendem tais matérias. Neste caso, como pode a sensação de parcialidade ser resultado de características da fonte, se a mesma mensagem pode ser vista como tendenciosa para um lado ou para o outro a depender do grupo em que o observador está inserido?

Na história da pesquisa sobre "news bias", começa-se a progredir na explicação das causas do sentimento de que a comunicação é tendenciosa apenas quando se propõe uma reviravolta nesta perspectiva. Como bem formulou Albert Gunther (1992, p. 148), "embora de valor inquestionável, a análise de conteúdo necessariamente se concentra, no processo de comunicação, na fonte da mensagem e uma perspectiva de pesquisa centrada na fonte nos inclina a perguntar o que as mensagens fazem às pessoas em vez de nos levar a indagar o que as pessoas fazem com as mensagens". Uma reviravolta algo copernicana, uma vez que se troca o centro de referência: em vez de centrarmos o foco no efeito da comunicação sobre as pessoas, colocamos em foco o que as pessoas fazem com a comunicação. Isto posto, começa-se a testar a hipótese de que a explicação da sensação de parcialidade do jornalismo não está estritamente relacionada às propriedades objetivas das notícias, mas poderá se revelar na análise das características de quem as lê, ouve ou vê.

A alternativa mais antiga a esta perspectiva consistiu em atribuir a sensação de parcialidade (e o ceticismo acerca do jornalismo) a certas tendências de determinadas audiências. Assim, certos grupos humanos - agrupados por características demográficas como fazer parte ou não de uma minoria política, idade, vínculo político, religião ou, até mesmo, grau de escolaridade - podem revelar maior ou menor grau de ceticismo ou de confiança na cobertura dos acontecimentos pelos jornais. Entretanto, quando tratadas estaticamente, as características do público demonstraram não ser um território sólido para se determinar a origem do ceticismo e a sensação de distorção voluntária. De fato, determinados estratos demográficos tendem a ser mais céticos com relação à cobertura de certos temas, mas não nos dispensa de explicar, com base em algum outro fator, como suas experiências históricas, por que minorias são mais céticas do que maiorias. O que há na condição de ser parte de um estrato ou minoria que induz os indivíduos a desconfiar da 
imparcialidade do jornalismo? Além disso, o ceticismo quanto à imparcialidade do jornalismo é disparadamente maior diante de certos conteúdos, como política, religião e esportes, e muito baixo diante dos outros. Uma evidência que não se explica em face de características demográficas. Os pontos cegos nesta alternativa levantaram a suspeita de que a origem e a persistência da sensação de parcialidade da cobertura de certos assuntos têm mais a ver com o envolvimento dos leitores, ouvintes ou espectadores de jornais com tais assuntos do que com outros fatores demográficos (Gunther, 1992, p. 147-148).

Se a explicação da sensação de que a comunicação é tendenciosa não encontra boas razões nos conteúdos dos meios de comunicação nem em características demográficas dos consumidores de mídia, que caminhos a investigação haveria de seguir?

A pesquisa contemporânea em comunicação e em psicologia social aplicada à comunicação vai sugerir que há dois mecanismos na base da sensação de que a comunicação é tendenciosa. O primeiro, que foge ao escopo deste trabalho, é o chamado TPE (third-person effect), a tendência a superestimar os efeitos de mensagens (negativas ou indesejadas) sobre os outros, em contraste com o efeito estimado em nós mesmos (GOMES; BARROS, 2014). O TPE acontece quando pessoas presumem que uma mensagem que veicula conteúdo por elas considerado negativo irá exercer influência real sobre os outros, embora não a exerçam sobre elas mesmas, e, por esta razão, pensam que devem tomar providências prévias para evitar que os outros (os vulneráveis) sejam expostos a tal conteúdo e aos seus efeitos (Davison, 1983).

O segundo mecanismo, que é considerado aqui, é a tendência de certas pessoas a ver distorção quando certos assuntos são tratados (Perloff, 1989, p. 238). Para a sensação de que a comunicação é tendenciosa não é relevante que, digamos, as novelas ou os jornais sejam efetivamente tendenciosos. O essencial, de fato, é apenas que as pessoas adotem elas próprias uma inclinação sobre certos assuntos que consideram sensíveis. Como diz Perloff, a "perception of media bias" é em geral derivada de uma "biased perception" que é própria do sujeito e do seu grupo de referência: "biased" grupos sempre verão a mídia como "biased", independentemente de haver ou não inclinação no conteúdo em questão. Em outras palavras, mesmo matérias e conteúdos que grupos neutros ou desinteressados 
asseguram ser imparciais ou equilibrados serão em geral vistos como tendenciosos por grupos que são, eles mesmos, fortemente tendenciosos.

\section{"Media bias or biased perception": A mídia é tendenciosa ou há uma percepção tendenciosa do fenômeno da distorção?}

Como tal aparente contrassenso se demonstra? Primeiro é fato que, ao contrário do que parece, não é todo mundo que vê o jornalismo ou a televisão como distorcidos, mas apenas certos indivíduos e em determinados casos. Mesmo nas circunstâncias em que esses indivíduos são numerosos, como em ambientes de grande polarização e de alta "temperatura" política, o sentimento de "media bias" será referido apenas a determinados conteúdos. Pois, então, quem são os indivíduos portadores deste sentimento? Os autores desta linha de pesquisa tendem a ser muito claros sobre quem são as pessoas naturalmente afetadas pela sensação de distorção da mídia. Albert Gunther (1992, p. 147), por exemplo, diz com todas as palavras que a desconfiança na correção da mídia, a sensação de que a mídia é parcial, normalmente é "consequência do envolvimento da pessoa com certos temas e com certos grupos". Premissa que vem sendo confirmada por sucessivos testes empíricos (Ross, Lepper, \& Hubbard, 1975; Vallone, Ross, \& Lepper, 1985; R. M. Perloff, 1989; Giner-Sorola \& Chaiken, 1994; Entman, 2007, 2010). O próprio Gunther (1988) constatou que "quanto mais polarizadas - em qualquer direção forem as posições assumidas pelas pessoas em face de um certo número de questões, como aborto ou políticas sociais, mais baixa será a sua confiança na cobertura dos meios de comunicação sobre tais questões".

$\mathrm{Na}$ literatura sobre o tema, formou-se forte consenso sobre o fato de que os portadores naturais da sensação de que a comunicação é distorcida são os "partidários" (partisans), as pessoas que têm ou tomam partido ante questões sobre os quais há clara divergência social. Além disso, podem ser definidos como "aqueles indivíduos altamente envolvidos que sustentam opiniões fortes e profundamente sentidas (deeply felt) sobre uma questão" (Schmitt, Gunther, \& Liebhart 2004, p. 623). Em alguns temas ou assuntos ou em 
algumas circunstâncias sociais e políticas (durante campanhas políticas ou militares, ante certos acontecimentos com grande impacto público, durante ondas de notícias sobre fatos que envolvam alta controvérsia moral ou política etc.), um grande número de pessoas pode assumir um ponto de vista partidário, uma perspectiva, portanto, que representa apenas uma das posições possíveis no tabuleiro do xadrez da política, dos valores e dos sentimentos. Já com relação a outros assuntos, menos destacados ou sobre os quais há amplo consenso social, ou em outras circunstâncias, quando a polarização e a polêmica não se fazem presentes, o número de "partidários" tende a ser muito menor ou insignificante.

Mas os partidários e os grupos a que eles pertencem nunca podem ser subestimados, não importa o seu número, como lembram Schmitt, Gunther \& Liebhart (2004, p. 624), uma vez que:

Os seus pontos de vista podem influenciar de forma poderosa a opinião pública e as políticas públicas; são eles que fazem campanhas e lobby, que fazem manifestações, desfiles e piquetes, que promovem os seus pontos de vista de inúmeras maneiras e, quando se sentem marginalizados ou excluídos, podem recorrer a ações extremas ou antissociais.

No caso brasileiro, por exemplo, foram os partidários e as suas convicções de que a mídia manipula e distorce que produziram o "Projeto de Lei de Iniciativa Popular da Comunicação Social Eletrônica". Ao fim e ao cabo este PL pode ser lido como um manifesto de partidários da esquerda tradicional sobre o "media bias" do rádio e da televisão no Brasil e sobre como isso deveria ser remediado legalmente.

Partidários certamente não podem ser considerados um grupo de observadores neutros da realidade. Aliás, como dizem Vallone et al., (1985, p. 577)

Os intérpretes sociais (social perceivers), tem sido há muito reconhecido, estão longe de serem pessoas que registram, de modo passivo e imparcial, os acontecimentos que transcorrem ao seu redor. Todo dia nos defrontamos com oportunidade de nos espantar com a capacidade que tem partidários políticos, sociais ou até mesmo do campo científico, de encontrar robustas confirmações 

desapaixonados acham confusos, contraditórios e totalmente inconclusivos.

Em suma, se eu acho a mídia parcial, isso não significa que, da minha parte, eu seja isento e imparcial. Assim, há que se incluir necessariamente na equação um sistema de referências subjetivo ou coletivo, um "eu" ou "nós" versus "ele" ou "eles". É a partir do nosso ponto de vista, das nossas convicções e do nosso sistema de valores que decidimos sobre a correção ou incorreção intelectual ou normativa do conteúdo do noticiário. Em geral, consideramos tendenciosa a notícia que contém uma inclinação adversária do que julgamos certo do ponto de vista axiológico (isto é, relacionado aos valores) ou cognitivo - é simples assim. Muito raramente consideramos e ainda mais raramente admitimos como tendenciosa uma matéria favorável às nossas convicções.

Admitido um sistema de referências, descobriu-se, portanto, que a sensação de que algo no noticiário está errado é diretamente vinculada à importância que atribuímos ao assunto do noticiário. Isso quer dizer que quando o assunto não nos importa ou afeta, a discrepância de pontos de vistas e valores se torna irrelevante e, por conseguinte, não haverá a sensação de que o noticiário é distorcido e adversário. Não só. Os pesquisadores descobriram que há uma escala de intensidade da sensação de distorção, correlacionada a outra escala de níveis de divergência moral e intelectual entre o noticiário e o nosso ponto de vista, correlacionada, por sua vez, ao nível de importância que nós atribuímos e ao grau da nossa implicação existencial, afetiva, emocional no assunto em tela. O quanto estamos envolvidos, engajados, comprometidos com o assunto do noticiário estabelece o nível do nosso interesse, da nossa atenção e da nossa susceptibilidade ao tratamento que lhe será oferecido. O que, ao fim e ao cabo, servirá como parâmetro para que estabeleçamos o grau de distorção do noticiário. Assim, quanto maior for a distância estimada entre o que consideramos certo (moral ou cognitivamente) e o que a notícia apresenta, maior será a sensação de que a notícia é tendenciosa e hostil, mas apenas quando o assunto da notícia nos interessa ou implica em um nível existencial e emocional relevante. 
Tomando como base as clivagens típicas do âmbito axiológico e político em nossas sociedades, é possível verificar os assuntos a que, mormente, somos muito sensíveis. Assim, as contraposições entre direita e esquerda, liberais e conservadores morais, e, por fim, entre religiosos e secularistas, por exemplo, podem dar os quadros da nossa localização e implicação pessoal nos temas do noticiário. Assim, um membro radical da esquerda será muito mais sensível a certas abordagens de conteúdos políticos do que um sujeito com uma posição de esquerda mais moderada. E um moderado de centro pode se sentir ainda menos implicado e menos disposto a oferecer endosso à condenação da "tendenciosidade" do noticiário em questão. Do mesmo modo, um religioso tolerante e secularizado será menos sensível a certos conteúdos e abordagens do que um crente fundamentalista, por exemplo, que se sentirá constantemente ofendido pela cobertura da "mídia liberal".

Naturalmente, não se trata aqui apenas das controvérsias morais permanentes da sociedade (GUTMANN; THOMPSON, 1996), mas de qualquer sistema de referência em que me engajo com maior ou menor entrega, como costuma acontecer, por exemplo, com o nosso juízo sobre a cobertura esportiva ou sobre o tratamento que "a mídia" dá aos nossos ídolos da música ou às nossas tendências musicais. Neste sentido, torcedores do Bahia e fãs de Justin Bieber não se sentem menos vítimas de um jornalismo adversário do que conservadores fundamentalistas e partidários do Partido dos Trabalhadores. A sensação de que o noticiário é adversário da minha posição não é exclusiva do âmbito político ou do campo moral, portanto, mas de qualquer esfera da vida em que as pessoas, por uma razão ou por outra, estejam engajadas e comprometidas em nível afetivo e axiológico: os jornais são contra o meu time, tanto quanto o são contra as minhas crenças, meu partido e a minha banda predileta.

Esta é a razão porque estudiosos de comunicação política e de psicologia social identificaram este fenômeno como, dentre outros rótulos, hostile media effect, hostile media bias, hostile media perception, algo como "sensação de mídia hostil" ou "sensação de distorção adversária da mídia”. Desde metade dos anos 1980 se vêm testando reiteradamente a sensação de que o noticiário é tendencioso (ou a persistente crença no "news bias") e a literatura internacional descobriu coisas muito interessantes a respeito 
desta disposição. Já em 1983, no célebre artigo em que formula o modelo do ThirdPerson Effect ${ }^{2}$, Davison registra e comenta os dois elementos fundamentais relacionados ao sentimento de que a mídia é tendenciosa: a ideia de distorção adversária e a previsão de efeitos intensos sobre terceiros. De fato, W. Phillips Davison (1983, p. 11) afirma que

\footnotetext{
“(...) uma explicação possível para o fato de que pessoas em lados opostos de uma questão podem ver os meios de comunicação como tendenciosos contra (biased against) os seus próprios pontos de vista é que cada observador presume que os argumentos ou fatos que apoiam o lado "errado" da questão irão conseguir um efeito enorme. Os outros (terceiros), pensa o observador, vão ser excessivamente impressionados por esses fatos ou argumentos, uma vez que não têm as informações que me permitem formar uma opinião correta".
}

Assim, em geral, quando um sujeito afirma a sua convicção de que o noticiário ou a novela são parciais ou tendenciosos não está fazendo ou pressupondo, de fato, um juízo sobre a natureza das notícias ou de uma cena ou personagem da telenovela, mas, principalmente, formulando ou supondo a convicção de que "a mídia é adversária da minha posição". Neste quadro, entende-se por que é possível uma emissora ofender e irritar contemporaneamente progressistas e reacionários, como nos recentes episódios de proposta de boicote à Rede Globo, apoiados ao mesmo tempo por petistas, black-blocs e fundamentalistas homofóbicos. A situação parece paradoxal, porque as posições mais conservadoras e mais progressistas chegaram a um firme consenso sobre o fato de os produtos da Rede Globo representarem valores, premissas e enquadramentos tendenciosos e adversários, tanto destes quanto daqueles. Os movimentos sociais e os envolvidos nos Protestos de Junho de $2013^{3}$ em geral consideravam que as manifestações, nas suas diversas fases, tiveram uma cobertura distorcida, amplamente desfavorável aos que neles estiveram envolvidos e às suas agendas. Falou-se, então, e se fala com muita frequência nesses ambientes, de "criminalização" das manifestações e dos movimentos sociais e dos coletivos organizados para o protesto de rua. Depois se falou que o noticiário teria "sequestrado" as manifestações, com enquadramentos positivos, mas diferentes dos propostos pelos envolvidos. Por fim, teria havido o retorno à “criminalização". Os petistas, particularmente, e os partidos de esquerda em geral, são constantes e enfáticos na crítica da "mídia conservadora" em virtude da cobertura política 
enviesada de que, supostamente, seriam vítimas. Muitos estão convencidos de “conspiração editorial contra o PT", na expressão popularizada em 2010, ou de que as grandes empresas de comunicação no país distorcem voluntariamente a cobertura política para desqualificar o "governo popular" do PT e para promover uma revanche contra o seu sucesso eleitoral, implementando com isso um desleal e antidemocrático "terceiro turno" eleitoral. É isso, afinal, o que quer dizer a expressão "PIG", acrônimo para Partido da Imprensa Golpista, altamente disseminado nas arenas públicas de esquerda. Da mesma queixa de distorção intencional e adversária partilham os conservadores fundamentalistas brasileiros, particularmente aqueles que levam a termo um conflito moral contra o reconhecimento e os direitos das pessoas homossexuais. Alegam que tanto o noticiário quanto a ficção televisiva da Rede Globo estão claramente orientados para distorcer a imagem dos evangélicos conservadores, negar espaço para as suas agendas e para promover as posições adversárias. A Rede Globo, com suas novelas e telejornais, faria, então, parte de uma grande conspiração das classes médias secularistas brasileiras para desqualificar as posições religiosas que defendem "valores familiares" e para incentivar e disseminar práticas e valores hostis "à família". De um lado, portanto, haveria a "perseguição religiosa" contra os religiosos fundamentalistas e, do outro lado, uma posição firmemente "gayzista" ou voltada para a "supremacia gay", conforme declarações disseminadas pelo líder religioso Silas Malafaia e pelo pastor e deputado federal Marco Feliciano.

O paradoxo se explica em face das clivagens de referências de cada grupo. Os religiosos fundamentalistas são extremamente sensíveis a conteúdos em que a sua agenda moral esteja implicada e, por conseguinte, estão sempre prontos para detectar o seu desacordo com uma representação favorável aos homossexuais nas novelas e com uma cobertura dos fatos do dia claramente condenatória da homofobia e da intolerância antihomossexual de origem religiosa. A sensação de distorção proposital e adversária do noticiário e da ficção é derivada imediatamente destas premissas. Na mesma linha, os manifestantes políticos, tanto faz se de esquerda ou de direita, estão implicados e comprometidos na cobertura dos seus protestos, uma vez que os entendem como parte da luta por reivindicações, agendas e reconhecimento social e político. Uma cobertura que adote uma seleção e um enquadramento divergente ou antagônico aos propósitos de 
comunicação dos manifestantes põe tudo a perder, pois é por meio do noticiário e não pela experiência direta dos protestos que Estado e sociedade formam as suas convicções sobre a natureza dos movimentos de rua e a justeza do que reivindicam ou manifestam. Novamente a fieira se estabelece: a sensibilidade a determinados assuntos é condição para a sensação de erro e, portanto, para a sensação de distorção.

\section{A direção do favorecimento}

$\mathrm{O}$ argumento popular afirma que noticiários, programas de auditórios, novelas, seriados, desenhos animados etc. refletem, em certos casos, uma inclinação intencional para favorecer uma perspectiva, um quadro ou grupos de interesses sociais, uma posição política, ideológica ou religiosa. E que, ao fazer isso, adotam uma posição adversária a todas as outras perspectivas e interesses presentes na sociedade. Vimos até agora como esta convicção afeta certo tipo de pessoas ou grupos e em determinadas circunstâncias. Além disso, vimos que a literatura sobre o tema descarta a plausibilidade de que esta convicção tenha um necessário e constante fundamento empírico. Este descarte, contudo, apoia-se, até este ponto do argumento, no fato de que a convicção não é universal, afetando com consistência apenas grupos sociais específicos: os partidários, as pessoas altamente envolvidas com um determinado assunto.

Mas há ainda outro argumento, testado em situações de laboratório, usado fortemente para atacar as pretensões de fundamentação empírica da sensação de mídia adversária: a questão do juízo sobre a direção do favorecimento. Desde os primeiros três conjuntos de estudos empíricos sobre a sensação de mídia hostil (Giner-Sorola \& Chaiken, 1994; R. M. Perloff, 1989; Vallone et al., 1985), pesquisas empíricas vêm replicando situações em que dois grupos de partidários, adversários entre si, expostos aos mesmos conteúdos veem um grau semelhante de parcialidade, mas divergem de forma diametralmente oposta sobre qual é o lado desfavorecido por ela.

Em palavras de Vallone, Ross, \& Lepper (1985), “(...) ambos os lados concordam que a cobertura foi enviesada, mas discordam tenazmente sobre a direção de viés". O que é 
uma situação mais comum do que parece. Os autores citados acima, por exemplo, examinaram as reações de um grupo de espectadores diante de um corpus formado por reportagens televisivas sobre um massacre de civis em campos de refugiados do Líbano em 1982, que claramente punha em questão os lados antagônicos pró-árabes e próisraelenses. Os partidários de um lado ou de outro concordaram intensamente no fato de as reportagens terem sido distorcidas intencionalmente, mas ambos reivindicaram que a distorção introduzida tinha como objetivo apresentar o próprio lado sob uma luz muito desfavorável. E concluíram que um espectador neutro tenderia para o lado do adversário se fosse exposto àquelas matérias.

Desde então, o antagonismo dos vetores do favorecimento vem sendo testado e comprovado empiricamente, em um significativo número de estudos (ARIYANTO; HORNSEY; GALLOIS, 2007; ARPAN et al., 2011; CHIA et al., 2007; GLYNN; HUGE, 2014; GUNTHER; CHIA, 2001; GUNTHER; LIEBHART, 2006; GUNTHER; SCHMITT, 2004; GUNTHER et al., 2001, 2012; HARTMANN; TANIS, 2013; MATHESON; DURSUN, 2001), inclusive por artigo de meta-análise que revisa 34 pesquisas sobre a percepção de mídia hostil (HANSEN; KIM, 2011).

\section{Previsão de dano}

A sensação de que o jornalismo favorece o lado contrário ao meu frequentemente implica a convicção de que um espectador, ouvinte ou leitor neutro seria levado a adotar uma atitude desfavorável ao meu lado. É o argumento, subsidiário, de que a mídia manipula. Este componente ("a tendência de ambos os grupos de afirmar que espectadores neutros vão se virar contra o lado deles quando virem a cobertura da mídia") - que vou chamar de "previsão de dano" - deve ser destacado, por representar uma das observações mais interessantes do estudo da sensação de parcialidade da mídia. Uma tendência que certamente explica a frustração, a irritação, o incômodo dos que estão convencidos de que um jornal, uma reportagem, um personagem, uma cena de telenovela - ou simplesmente a integralidade dos meios de comunicação - são tendenciosos contra o ponto de vista que 
eles consideram justo. Neste sentido, o partidário projeta o dano que tal distorção haverá de produzir contra o seu lado, aliciando ou predispondo de forma hostil ou adversária ao seu ponto de vista os incautos neutros ou desinformados. Naturalmente, quanto mais vulnerabilidade (aos engenhos e artifícios da mensagem distorcida) se atribuir aos não partidários, maior o incômodo e a insatisfação com os meios de comunicação. Em geral, a lista padrão dos grupos considerados muito vulneráveis incluem, ao gosto de quem emite o juízo, crianças e jovens, pobres, pessoas com baixa escolarização ou baixa renda e pessoas com pouca informação ou interesse político. Esses, sim, estimamos que passarão rapidamente para o lado adversário - e errado, claro - assim que forem submetidos às mensagens dos meios de comunicação.

Previsto o dano, pode-se passar à tomada de atitudes. Como a literatura sobre TPE (thirdperson effect) fartamente documentou, as estimativas sobre efeitos poderosos e nocivos das mensagens sobre terceiros estão em geral correlacionadas positivamente com o apoio à censura e ao controle de conteúdo (ROJAS; SHAH; FABER, 1996; SALWEN; DRISCOLL, 1997; SALWEN, 1998). Além disso, tanto elites quanto minorias políticas costumam reagir quando sentem que são objeto de cobertura negativa (quando se trata de jornais) ou de representação desfavorável (quando se trata de ficção). Ambas, elites e minorias, costumam reagir atacando a fonte, afirmando e difundindo a ideia de que um determinado veículo, ou os meios de comunicação como um todo, são parciais e inexatos. Glen Smith, por exemplo, documentou como as elites atacam as fontes que consideram adversárias (SMITH, 2010), enquanto, por outro lado, temos múltiplos exemplos acontecendo agora no laboratório social brasileiro sobre como os movimentos de protesto e grupos de interesses promovem o discurso social sobre "a criminalização dos movimentos sociais", a "perseguição editorial contra os partidos de esquerda" - além, naturalmente, da franca hostilidade contra profissionais da imprensa e empresas de comunicação durante manifestações de rua e em sites de redes sociais. Naturalmente, atacar a mídia adversária (que na perspectiva do grupo que se considera perseguido é um justo e devido contra-ataque) é, antes tudo, produzir um discurso que seja favorável e conveniente (self-serving) ao próprio lado. Por outro lado, ataques constantes não deixam de ter grande parte da responsabilidade pela persistência e disseminação da sensação 
generalizada de que os meios de comunicação são parciais e meios de manipulação de corações e mentes.

Por fim, entra na lista das medidas de prevenção de dano um conjunto de medidas corretivas (BARNIDGE; ROJAS, 2014; ROJAS, 2010) como, tentativas de corrigir o que se tem como erros difundidos pela mídia por meio do aumento exponencial, em todas as arenas da esfera pública, da presença da parte que se acha lesada na esfera midiática. Rojas e Barnidge, por exemplo, demonstraram que portadores de altos níveis de sensação de mídia hostil e de suposições sobre a influência da mídia sobre terceiros falam com mais frequência sobre política e se munem com o maior número de pontos de vista em conversações sobre política. E ocupam mais largamente os sites e aplicativos de redes sociais digitais, poderíamos acrescentar.

\section{Parcialidade ou erro?}

Além disso, embora a sensação de que o noticiário seja enviesado aparentemente reivindique uma posição imparcial, não se trata, na verdade, de nada disso. Reiteradas vezes os pesquisadores identificaram que o portador da sensação de distorção adversária do noticiário considera a imparcialidade uma posição tendenciosa. É um paradoxo que uma posição muito sensível à parcialidade, rejeite, ao mesmo tempo, a imparcialidade. Mas não deixa de fazer sentido, uma vez que, neste caso, a aparente tese cognitiva (ou gnosiológica) é, na verdade, uma tese moral. Em suma, pode tratar-se menos de erro cognitivo do que erro moral. O erro cognitivo, quando é causado por parcialidade, corrige-se trazendo a compreensão para o ponto justo e adequado - a imparcialidade é a meta. Mas em campo moral, a contraposição entre certo e errado não permite imaginar que um meio termo entre ambos seja a posição adequada - meio errado não é igual a certo.

Assim, quando consideramos que os valores e os princípios corretos estão em causa, consideramos também que tentar ser imparcial e equilibrado com os valores e princípios em disputa é ser injusto com a posição correta. Por que, por exemplo, dar voz aos 
fundamentalistas homofóbicos na interpretação dos fatos, colocando-os - e à sua posição - em pé de igualdade com as perspectivas pró-direitos e pró-respeito e tolerância? Posições antidemocráticas (machistas, racistas, preconceituosas, ofensivas) devem ter as suas razões consideradas e justificadas na busca de uma posição neutra e imparcial no jornalismo? Em geral, responderíamos não às perguntas acima, isso porque o nosso lado já está escolhido e consideramos corretos os valores em que nos engajamos. Se estivéssemos na outra margem do rio, o nosso julgamento sobre parcialidade e imparcialidade poderia ser outro.

Assim, quando há divergência moral entre nossa posição e a que julgamos representada nas notícias, a parcialidade é vista com um defeito moral do noticiário, mas a tentativa de imparcialidade ou neutralidade não seria julgada com menor severidade. O que nos revela que, afinal, quando temos a sensação de que o noticiário é distorcido não está realmente em jogo a questão da parcialidade, uma vez que está claro que nem a imparcialidade nem a neutralidade remediariam a sensação; o que está em questão aqui é tão somente a certeza subjetiva de haver um erro, uma falha moral ou intelectual, uma distância moral e cognitiva entre nossas convicções do que é certo e justo e o que a matéria retrata, sustenta, defende ou sugere. Uma distorção peculiar esta, que não se corrige com isenção, mas com a adoção da nossa posição ou, no mínimo, com um grau zero de reservas e dúvida quanto a ela.

O fato é que a sensação de distorção se dá sempre na presença de outra variável, a saber, a convicção (subjetiva ou coletiva) de que o noticiário, o veículo ou a matéria que considero tendenciosa contém um erro. O noticiário que considero tendencioso sempre está errado, moral e/ou cognitivamente, e é justamente por esta razão que não admito tratar-se de mera inclinação, mas de distorção voluntária, de vício, de uma ação inapropriada. O sentimento de que esta matéria é tendenciosa, portanto, é sempre acompanhada pela convicção de que alguma coisa na matéria (enquadramento, interpretação, quadro moral, premissas) está errada. Por outro lado, na ausência desta convicção, a sensação de distorção desaparece - o "bias" do noticiário, portanto, é curiosamente apenas para o erro, nunca para a virtude. 


\section{A fonte importa?}

Por fim, há o argumento sobre a fonte ou a origem do material que se considera tendencioso e destinado a favorecer o partido oposto. Quem está convencido de que a mídia é hostil ao seu lado acredita que a preferência pelo outro partido, que ele percebe nos conteúdos da comunicação, é um fato objetivo. Por esta razão, tem certeza de que a fonte de tal conteúdo é absolutamente irrelevante para a sua convicção sobre a inclinação adversária dos materiais distribuídos pela mídia. Em outras palavras, um relato inexato e parcial sobre os fatos não é inexato nem parcial por ser do jornalismo ou da televisão, mas pelas suas qualidades intrínsecas. Será mesmo? Autores têm procurado examinar a premissa da irrelevância da fonte para o sentimento de mídia adversária, com conclusões que merecem reflexão.

Alguns estudos examinaram diferentes fontes jornalísticas, como noticiário esportivo em contraste com o noticiário sobre temas de política, jornais locais em contraste jornais de alcance nacional (ARPAN; RANEY, 2003), chegando à conclusão de que fontes e circunstâncias da notícia importam, sim, além da conclusão adicional de que partidários da área de esportes são tão afetados pela síndrome de mídia hostil quanto os partidários políticos ${ }^{4}$. Outro estudo, liderado por pesquisadora da Indonésia, mostrou como muçulmanos e cristãos leram um artigo descrevendo conflitos inter-religiosos. Neste artigo ela observa que a mesma matéria foi vista como tendenciosa a favor do Islã quando atribuída a jornais muçulmanos, mas a favor dos cristãos quando atribuída a um jornal cristão. Por outro lado, os entrevistados já não tinham tanta certeza de haver inclinação, quando o jornal não era identificado (ARIYANTO; HORNSEY; GALLOIS, 2007).

Mas a demonstração mais cabal consta em dois artigos recentes, (Gunther \& Schmitt, 2004; GUNTHER \& LIEBHART, 2006), em que os pesquisadores testaram o pressuposto da indiferença da fonte, submetendo diferentes grupos de entrevistados ao mesmo material de estímulo: um relato sobre alimentos geneticamente modificados. Para alguns grupos, o material distribuído foi apresentado como sendo um artigo de jornal, enquanto para outros, o relato foi apresentado como um trabalho de estudante de graduação. O resultado foi que a sensação de distorção e favorecimento dos adversários 
desapareceu quando os entrevistados não consideravam o relato como proveniente da mídia. Antes, houve até uma certa inversão na estimativa do lado favorecido. Isso levou os autores à conclusão de que, sim, para os partidários os conteúdos da mídia são considerados distorcidos e adversários porque são "da mídia" e não em virtude das suas qualidades estruturais.

Isso levou à formulação do princípio do "alcance percebido" (perceived reach) como moderador da hipótese da HMP: a suposição de que a mensagem é distorcida contra o meu lado é dependente de como eu avalio o alcance do canal por meio do qual a mensagem circula. "Por este modo de pensar, um canal de baixo alcance, um com pouca ou nenhuma audiência aparente externa, é visto com um olhar benévolo", dizem Gunther e Liebhart, enquanto o processamento de informação que circula por canais de largo alcance e que fala para uma audiência ampla é julgado de forma completamente diferente. E sugerem que quatro convicções estão por trás do modo suspeitoso e hostil com que os conteúdos da mídia são tratados por partidários: a) Partidários são muito particularmente susceptíveis à opinião dos outros e se preocupam muito com que os outros pensam sobre os conteúdos que lhe importam, ainda mais quando se trata da opinião pública, e sobre assuntos e grupos que lhes são especialmente caros; b) $\mathrm{O}$ contexto dos meios de massa ativa a atenção dos partidários sobre o potencial que os conteúdos da comunicação massiva têm de influenciar públicos muito amplos; c) Altamente envolvidos e compromissados com um tema ou causa, os partidários, por outro lado, são propensos a achar que as outras pessoas são menos informadas e, portanto, mais vulneráveis, especialmente quando se trata de opiniões por eles consideradas enganosas ou erradas; d) Como resultado dessas premissas, consciente ou inconscientemente, os partidários passam a adotar uma estratégia de processamento de informação fortemente defensiva. Assim,

Um conteúdo que em outro contexto parece aceitável, em vez disso parece marcadamente desfavorável - tendencioso, inexato ou incompleto e, portanto, potencialmente enganoso. Desse modo, apesar de uma informação comum parecer neutra e até mesmo favorável, no contexto dos meios de massa ela irá parecer ter inclinações para o lado que não nos favorece. (GUNTHER; LIEBHART, 2006) 
Em síntese, o argumento popular consiste em afirmar que "a mídia" (em geral, o jornalismo, mas, como vimos, também a ficção) não apresenta um retrato verdadeiro dos fatos. É o argumento cético. Isto ocorreria, diz-se, em virtude de intervenções conscientes que, de um lado, refletem as preferências e valores dos profissionais e das empresas de comunicação, ou de grupos e partidos que eles representem, e, por outro lado, têm o propósito de conduzir corações e mentes a adotar os valores e as perspectivas que são convenientes a específicos grupos de interesse político, ideológico, econômico etc. $\mathrm{Na}$ primeira parte, vimos o "argumento da inclinação intencional", na segunda, o "argumento da manipulação mediática". A inclinação voluntária e intencional (bias) conduz fatalmente ao favorecimento de uma perspectiva ou interesse social e político e, por conseguinte, ao desfavorecimento de toda perspectiva ou interesse contrário; ao adotar um dos lados, os conteúdos dos meios de comunicação se tornariam adversários de todos os outros: daí a ideia de que os meios de comunicação são hostis.

O "argumento cético" é a perspectiva de fundo para muitos outros princípios e atitudes que não apenas à ideia de inclinações propositais que terminam em favorecimento/perseguição de pontos de vistas e valores. Antes, um certo grau de ceticismo é considerado benéfico à democracia, conforme argumenta Michael Schudson (SCHUDSON, 2008). Mas o ceticismo também leva à apatia e ao cinismo (LEE, 2010; LENGAUER; ESSER; BERGANZA, 2011; TSFATI; COHEN, 2012; TSFATI, 2003), como fartamente documentado, ou, o que provavelmente é um maior dano, à percepção dos meios comunicação como importantes adversários, não como aliados e instrumentos, da democracia. A desqualificação generalizada e global da comunicação como imprestável e perigosa para a democracia é o correspondente à desqualificação, igualmente genérica e simplificada, da política e dos políticos como nocivos à democracia. Aliás, não parece haver ganho para a democracia justamente na degradação recíproca e constante entre política e mídia que se processa nesses dias.

Existe inclinação, tratamento preferencial, erro e manipulação no jornalismo, nos programas de auditório e na ficção. Se, a este ponto do argumento, ainda for necessário, convém esclarecer que este ensaio não trata da questão se o jornalismo e os meios de 
comunicação, genericamente, ou se determinadas matérias, enfoques e enquadramentos, em particular, sofrem de distorção e parcialidade proposital. Nos ocupou aqui exclusivamente a natureza da premissa interpretativa segundo a qual a comunicação é sistematicamente orientada para favorecer o lado adversário àquele do observador, revisando um corpus consistente de literatura segundo a qual tal premissa, contrariamente à opinião comum, revela muito mais sobre a estrutura intersubjetiva da interpretação da mídia, por parte de partidários e dos coletivos onde eles estão inseridos e engajados, do que sobre valores e comportamentos intrínsecos do jornalismo e da ficção, de suas empresas e seus profissionais.

\section{Agradecimentos e Observações}

Este artigo foi profundamente beneficiado pela leitura cuidadosa e as críticas consistentes de Maria Paula Almada, Samuel Barros e Camilo Aggio.

\section{Notas}

1 Ver também, do mesmo autor, (GUNTHER, CHRISTEN, LIEBHART, \& CHIA, 2001; GUNTHER, EDGERLY, AKIN, \& BROESCH, 2012)

${ }^{2}$ Um dos modelos teórico-metodológicos mais empregados hoje no campo dos "media effects" (a pesquisa sobre a influência da comunicação).

${ }^{3}$ Onda de protestos políticos que ocuparam simultaneamente as ruas e as arenas sociais digitais brasileiras, cujo início e ápice se deram em junho de 2013 (Para mais informações, cf. GOMES, 2014).

${ }^{4}$ A propósito disso, é sempre importante lembrar que a inspiração dos primeiros estudos sobre o efeito de mídia vem do famoso estudo de caso "They Saw a Game" (HASTORF; CANTRIL, 1954) sobre como torcedores de dois times universitários rivais interpretaram um jogo e reagiram ao noticiário sobre a partida.

\section{Referências}

ARIYANTO, A.; HORNSEY, M. J.; GALLOIS, C. Group Allegiances and Perceptions of Media Bias: Taking Into Account Both the Perceiver and the Source. Group Processes \& Intergroup Relations, v. 10, n. 2, p. 266-279, 1 abr. 2007.

ARPAN, L. M. et al. Perceptions of Bias in Political Content in Late Night Comedy Programs. Electronic News, v. 5, n. 3, p. 158-173, 19 set. 2011.

ARPAN, L. M.; RANEY, A. A. An Experimental Investigation of News Source and the Hostile Media Effect. Journalism \& Mass Communication Quarterly, v. 80, n. 2, p. 265-281, 1 jun. 2003.

BARNIDGE, M.; ROJAS, H. Hostile Media Perceptions, Presumed Media Influence, and Political Talk: Expanding the Corrective Action Hypothesis. International Journal of Public Opinion Research, 13 mar. 2014. 
CHIA, S. C. et al. Personal Bias or Government Bias? Testing the Hostile Media Effect in a Regulated Press System. International Journal of Public Opinion Research, v. 19, n. 3, p. 313330, 29 jul. 2007.

DAVISON, W. P. The Third-Person Effect in Communication. Public Opinion Quarterly, v. 47, n. 1, p. 1-15, jan. 1983.

ENTMAN, R. M. Framing Bias: Media in the Distribution of Power. Journal of Communication, v. 57, n. 1, p. 163-173, mar. 2007.

ENTMAN, R. M. Media framing biases and political power: Explaining slant in news of Campaign 2008. Journalism, v. 11, n. 4, p. 389-408, 17 ago. 2010.

GINER-SOROLA, R.; CHAIKEN, S. The causes of hostile media judgments. Journal of Experimental Social Psychology, v. 30, p. 165-180, 1994.

GLYNN, C. J.; HUGE, M. E. How Pervasive Are Perceptions of Bias? Exploring Judgments of Media Bias in Financial News. International Journal of Public Opinion Research, 17 fev. 2014.

GOMES, W. A política na timeline. Salvador: EDUFBA, 2014.

GOMES, W.; BARROS, S. Influência da mídia, distância moral e desacordos sociais: um teste do Efeito de Terceira Pessoa. In: FRANÇA, V. V.; ALDÉ, A.; RAMOS, M. C. (Eds.). . Teorias da comunicação no Brasil. Salvador: Edufba, 2014. p. 245-266.

GUNTHER, A. C. Biased Press or Biased Public? Attitudes Toward Media Coverage of Social Groups. Public Opinion Quarterly, v. 56, n. 2, p. 147, jan. 1992.

GUNTHER, A. C. et al. Congenial Public, Contrary Press, and Biased Estimates of the Climate of Opinion. The Public Opinion Quarterly, v. 65, n. 3, p. 295-320, 2001.

GUNTHER, A. C. et al. Partisan Evaluation of Partisan Information. Communication Research, v. 39, n. 4, p. 439-457, 10 abr. 2012.

GUNTHER, A. C.; CHIA, S. C. Predicting Pluralistic Ignorance: The Hostile Media Perception and its Consequences. Journalism \& Mass Communication Quarterly, v. 78, n. 4, p. 688-701, 1 dez. 2001.

GUNTHER, A. C.; LIEBHART, J. L. Broad Reach or Biased Source? Decomposing the Hostile Media Effect. Journal of Communication, v. 56, n. 3, p. 449-466, set. 2006.

GUNTHER, A. C.; SCHMITT, K. Mapping Boundaries of the Hostile Media Effect. Journal of Communication, v. 54, n. 1, p. 55-70, 1 mar. 2004.

GUTMANN, A.; THOMPSON, D. Democracy and disagreement. Cambridge, Ma: Harvard University Press, 1996.

HANSEN, G. J.; KIM, H. Is the Media Biased Against Me? A Meta-Analysis of the Hostile Media Effect Research. Communication Research Reports, v. 28, n. 2, p. 169-179, 27 abr. 2011.

HARTMANN, T.; TANIS, M. Examining the Hostile Media Effect as an Intergroup Phenomenon: The Role of Ingroup Identification and Status. Journal of Communication, v. 63, n. 3, p. 535555, 29 jun. 2013. 
HASTORF, A. H.; CANTRIL, H. They saw a game: a case study. The Journal of Abnormal and Social Psychology, v. 49, n. 1, p. 129-134, 1954.

LEE, T.-T. The Liberal Media Myth Revisited: An Examination of Factors Influencing Perceptions of Media Bias. Journal of Broadcasting \& Electronic Media, v. 49, n. 1, p. 43-64, mar. 2005.

LEE, T.-T. Why They Don't Trust the Media: An Examination of Factors Predicting Trust. American Behavioral Scientist, v. 54, n. 1, p. 8-21, 16 set. 2010.

LENGAUER, G.; ESSER, F.; BERGANZA, R. Negativity in political news: A review of concepts, operationalizations and key findings. Journalism, v. 13, n. 2, p. 179-202, 22 nov. 2011.

MATHESON, K.; DURSUN, S. Social Identity Precursors to the Hostile Media Phenomenon: Partisan Perceptions of Coverage of the Bosnian Conflict. Group Processes \& Intergroup Relations, v. 4, n. 2, p. 116-125, 1 abr. 2001.

PERLOFF, R. M. Ego-Involvement and the Third Person Effect of Televised News Coverage. Communication Research, v. 16, n. 2, p. 236-262, 1 abr. 1989a.

PERLOFF, R. M. Ego-Involvement and the Third Person Effect of Televised News Coverage. Communication Research, v. 16, n. 2, p. 236-262, 1 abr. 1989b.

ROJAS, H. "Corrective" Actions in the Public Sphere: How Perceptions of Media and Media Effects Shape Political Behaviors. International Journal of Public Opinion Research, v. 22, n. 3, p. 343-363, 12 ago. 2010.

ROJAS, H.; SHAH, D. V.; FABER, R. J. For the Good of Others: Censorship and the ThirdPerson Effect. International Journal of Public Opinion Research, v. 8, n. 2, p. 163-186, 1 jun. 1996.

ROSS, L.; LEPPER, M. R.; HUBBARD, M. Perseverance in self-perception and social perception: biased attributional processes in the debriefing paradigm. Journal of personality and social psychology, v. 32, n. 5, p. 880-92, nov. 1975.

SALWEN, M. B. Perceptions of Media Influence and Support for Censorship: The Third-Person Effect in the 1996 Presidential Election. Communication Research, v. 25, n. 3, p. 259-285, 1 jun. 1998.

SALWEN, M. B.; DRISCOLL, P. D. Consequences of third-person perception in support of press restrictions in the O. J. Simpson trial. Journal of Communication, v. 47, n. 2, p. 60-78, jun. 1997.

SCHMITT, K. M.; GUNTHER, A. C.; LIEBHART, J. L. Why Partisans See Mass Media as Biased. Communication Research, v. 31, n. 6, p. 623-641, 1 dez. 2004.

SCHUDSON, M. Why Democracies Need an Unlovable Press. Cambridge: Polity Press, 2008.

SMITH, G. R. Politicians and the News Media: How Elite Attacks Influence Perceptions of Media Bias. The International Journal of Press/Politics, v. 15, n. 3, p. 319-343, 30 jun. 2010.

TSFATI, Y. Media Skepticism and Climate of Opinion Perception. International Journal of Public Opinion Research, v. 15, n. 1, p. 65-82, 1 mar. 2003. 
TSFATI, Y.; COHEN, J. The Third-Person Effect, Trust in Media and Hostile Media Perceptions. Oxford, UK: John Wiley \& Sons, Ltd, , 28 dez. 2012. (Nota técnica).

VALLONE, R. P.; ROSS, L.; LEPPER, M. R. The hostile media phenomenon: Biased perception and perceptions of media bias in coverage of the Beirut massacre. Journal of Personality and Social Psychology, v. 49, n. 3, p. 577-85, set. 1985.

\section{O autor}

Wilson Gomes é professor titular da UFBA, coordenador do Instituto Nacional de Ciência e Tecnologia em Democracia Digital, pesquisador CNPq 1-A e professor nas áreas de comunicação política, internet e política e democracia digital. wilsonsg@terra.com.br 